\title{
Type A aortic dissection: New surgical strategy using intra-operative stenting
}

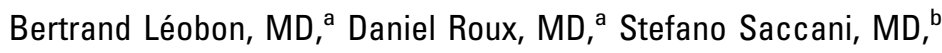 \\ Antoine Mugniot, MD, ${ }^{a}$ Fabrice Muscari, MD, ${ }^{a}$ Yves Glock, MD, PhD, ${ }^{a}$ and \\ Gérard Fournial, MD, ${ }^{a}$ Toulouse, France, and Parma, Italy
}

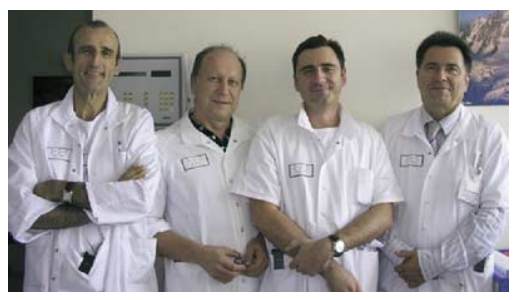

D. Roux, Y. Glock, B. Léobon, G. Fournial (left to right)

A

cute type A aortic dissection is a surgical emergency. After replacement of the ascending aorta, the arch and descending aorta often remain dissected, with a $40 \%$ risk of aneurysmal evolution at 5 years. Procedural dissections of arteries (coronary, renal, iliac) are treated with uncovered stents. Experimental studies on aortic dissections report suppression of false lumen and histologic cicatrization of stented aortas after 6 weeks. ${ }^{1,2}$ On the basis of these facts, our strategy was to support aortic cicatrization and prevent aortic dilatation. During surgical replacement of the ascending aorta with circulatory arrest, we have implanted uncovered stents in the true lumen of the dissected arch or descending aorta as described for the first 5 patients. ${ }^{3-5}$ Unlike stent grafts that cover entries, these stents were used to join the two dissected layers without compromising perfusion in the collateral arteries, especially in the aortic arch. The aim of our retrospective study was to assess feasibility and to analyze clinical and pathophysiologic results in the first 16 patients treated with this combined procedure.

\section{Patients and Methods}

From November 9, 2000, to September 1, 2004, 16 patients with acute type A aortic dissections have been treated with combined procedures. They underwent replacement of the ascending aorta and implantation of Djumbodis stents (Saint Côme Chirurgie, Marseille, France) (Figure 1). Stent implantations were achieved during complete circulatory arrest with deep hypothermia (12 patients) or partial circulatory arrest with antegrade cerebral perfusion (4 patients), according to the practices of the surgeons. Stent implantation took less than 2 minutes and was checked by direct vision (aortic arch) or radioscopy (descending aorta). Three patients were women $(19 \%)$. Average age was 57.3 years $( \pm 10.6)$. Average EuroSCORE was $9.4 \pm 2.9$. Before the operation, the patients had important aortic regurgitation $(\mathrm{n}=2)$, pericardial blood effusions $(n=4)$, myocardial infarctions $(n=2)$, stroke (

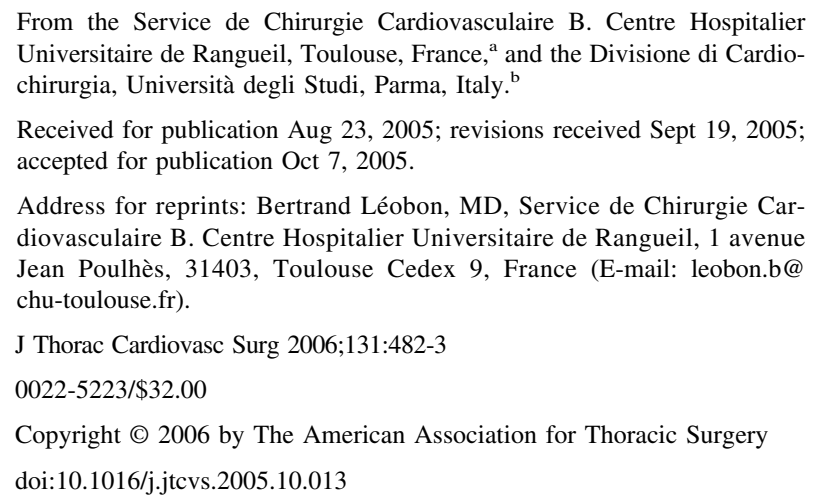

$=1)$, paraplegias $(\mathrm{n}=2)$, and lower limb ischemia $(\mathrm{n}=3)$. All patients had a dissection involving the whole aorta except for 1 patient without dissection of the descending aorta.

\section{Results}

Duration of circulatory arrest was 28.9 minutes $( \pm 10.8)$ at $14^{\circ} \mathrm{C}$ to $23^{\circ} \mathrm{C}$ for complete circulatory arrest and 25 minutes $( \pm 12.5)$ at $25^{\circ} \mathrm{C}$ for partial circulatory arrest. Fifteen stents were implanted in aortic arches and 3 stents in descending aortas. There were 2 intraoperative deaths $(12.5 \%), 1$ caused by unstoppable hemorrhage and 1 caused by myocardial infarction despite an aortacoronary bypass. Intensive care unit stay was 9.2 days $( \pm 6)$. Postoperative complications were respiratory $(9 / 16)$, renal failure $(6 / 16)$, and stroke (1/16). Two patients died after discharge, on days 15 and 16, and no autopsy was obtained. One patient died 95 days after the operation of a cerebral hemorrhage without cardiac or carotid etiology. After stenting of the arch, all supra-aortic trunks were patent on baseline computed tomographic (CT) scans. Median follow-up was 329 days ( \pm 310$)$. Thirty-day mortality was $25 \%$ (4/16). Cumulate survival (Kaplan-Meier) was $77.9 \%$.

Both preoperative and postoperative most recent $(159 \pm 96$ days) CT scans were available for 13 of the 16 patients (2 intraoperative deaths and 1 unavailable CT scan). The patient without dissection of the descending aorta was excluded from the following comparisons. In all 12 remaining cases, aortic arches received a stent, whereas none of these descending aortas was treated. Comparison between preoperative and postoperative CT scans showed that the circulating false lumen disappeared in 8 of the stented aortic arches $(66.7 \%)$ (Figure 2) and only 5 in the nonstented descending aortas $(41.7 \%)\left(\chi^{2}, P=.0384\right)$. The maximal diameters of the 12 stented aortic arches regressed $-3.00 \mathrm{~mm}$ $( \pm 5.97)$ whereas the maximal diameters of the 12 nonstented descending aortas increased $+1.17 \mathrm{~mm}( \pm 3.71)$ (Student $t$ test: $P$ $=.0070)$.

\section{Comments}

Despite the small number of patients, morbidity and mortality are in agreement with standard results in the literature and in our institutions for aortic dissection surgery. Technical feasibility is good, with correct durations of circulatory arrest and no major drawbacks concerning stent implantation taking less than 2 minutes.

Regarding pathophysiology, a favorable effect has been shown on false lumen occlusion and aortic diameter, with significant differences between stented and untreated segments in the same patients.

Mechanisms of action are different between uncovered stents and stent grafts. A stent graft occludes an entry and reduces flow and pressure in the false lumen, leading to its thrombosis. Here, the 


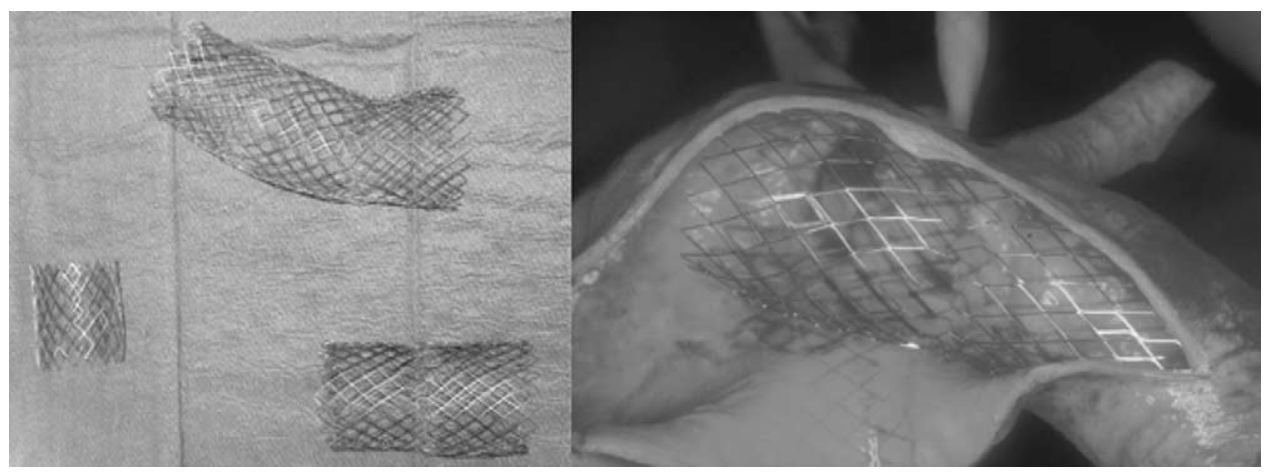

Figure 1. Left, Three sizes of Djumbodis stents $(4,9$ and $14 \mathrm{~cm})$. They can adapt from 20 to $50 \mathrm{~mm}$ in diameter as they are delivered on compliant Latex balloons. Right, Stent implantation in a cadaver aorta. Note permeability of the supra aortic trunks.
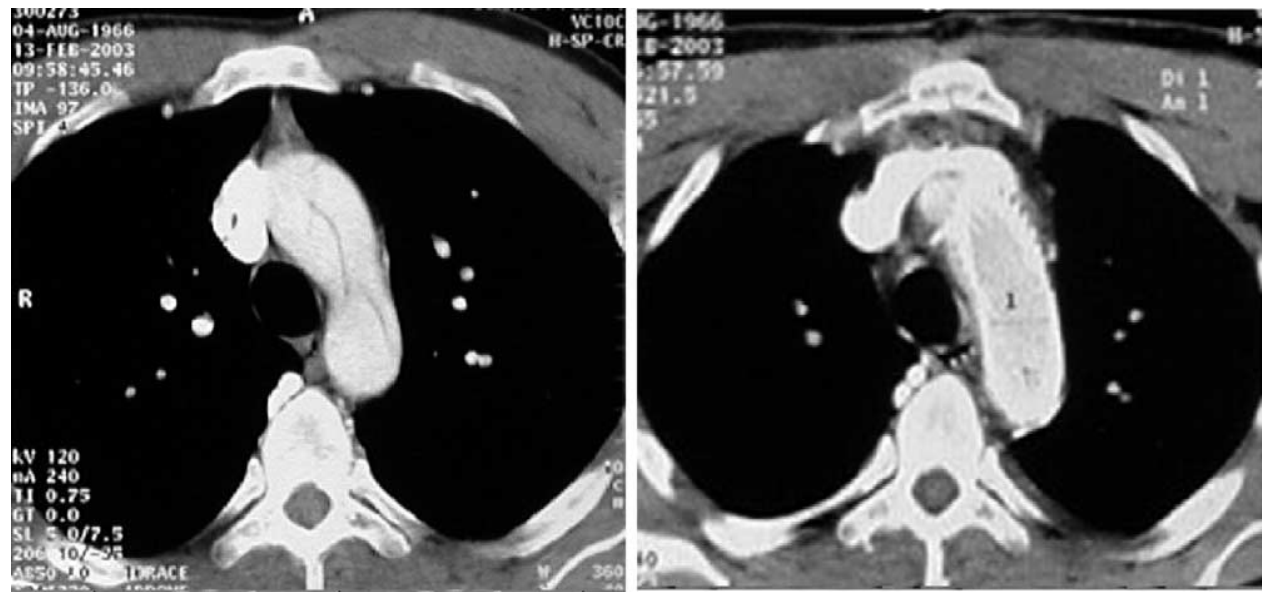

Figure 2. Left, Type A aortic dissection involving aortic arch before treatment. Right, After replacement of the ascending aorta and intra-operative stenting of the aortic arch, the false lumen has disappeared (Università degli Studi, Parma).

uncovered stent joins the dissected layers despite entries. It contributes to aortic reinforcement and cicatrization, as shown experimentally. ${ }^{1,2}$ This cicatrization seems preferable to aortic replacement by a prosthesis or implantation of a stent graft because it preserves collateral arteries and may also restore perfusion in branches closed by dynamic occlusions.

Our conclusion is that this combined procedure is feasible and supports aortic restoration. We think such stenting should be extended to the whole dissected aorta.

We thank the Hospital of Rangueil (Toulouse, France), the Paul Sabatier University (Toulouse, France), la Università degli Studi (Parma, Italia), and the experimental surgery laboratory of Rangueil for their support.

\section{References}

1. Trent MS, Parsonnet V, Shoenfeld R, Brener BJ, Eisenbud DE, Novick $\mathrm{AS}$, et al. A balloon-expandable intravascular stent for obliterating experimental aortic dissection. J Vasc Surg.1990;11:707-17.

2. Marty-Ane C, Serres-Cousine O, Laborde JC, Costes V, Alauzen M, Mary H. Use of endovascular stents for acute aortic dissection: an experimental study. Ann Vasc Surg. 1994;8:434-42.

3. Roux D, Brouchet L, Concina P, Elghobary T, Glock Y, Fournial G. Type-A acute aortic dissection: combined operation plus stent management. Ann Thorac Surg. 2002;73:1616-8.

4. Saccani S, Nicolini F, Borrello B, Agostinelli A, Larini P, Marcato C, et al. New technologies for the treatment of type A aortic dissection: a case report. J Thorac Cardiovasc Surg. 2004;127:1821-3.

5. Saccani S, Busi M, Fragnito C, Agostinelli A, Borrello B, Nicolini F, et al. Surgical repair and stent positioning for type A acute aortic dissection: a step forward? Ann Thorac Surg. 2005;79:1761-3. 